\title{
MATHEMATICAL MODELING OF GRADUAL IGNITION PROCESS AND UNSTEADY EROSIVE BURNING OF GUNPOWDER CHARGE AT TRIGGERED ARTILLERY SHOT
}

I. G. Rusyak, Kalashnikov Izhevsk State Technical University, Izhevsk, Russian Federation, primat@istu.ru

\begin{abstract}
The paper describes issues of mathematical modeling of the intraballistic artillery process at triggered artillery shot for various constructions of the charge. Formulation of the problem based on the description of intrabarrel flow by position of mechanics of heterogeneous mediums and multispeed continuum is presented. A general system of equations was obtained in the one-dimensional approximation, describing the unsteady movement of two-phase gas gunpowder mixture in the barrel and justice for various, including combined, charge structures. Specification of functions for mass, power and energy interaction between the combustion products and gunpowder components with different shapes was carried out. The conjugate problem formulation for gas dynamics of gradual ignition, unsteady and erosive burning of gunpowder was formulated. The full problem definition includes unsteady processes of heat distribution and chemical transformation in the $k$-phase in a blowing factor. The process of heating and burning for $k$-phase is considered within the local solid-phase A.G. Merzhanov - F.I. Dubovitskiy model. Erosive burning effects are modeled from position of J. Lenoir - J. Robilliard - G.K. Karakozov approach.

Keywords: mathematical modeling, internal ballistics, artillery systems, mechanics of heterogeneous mediums, ignition, burning, heat and mass exchange, conjugate problem.
\end{abstract}

\section{Introduction}

An improvement of igniting devices takes important place in practice of improvement of charges in artillery systems. This fact is determined by the contribution which is made by the process of warming up, ignition and subsequent unsteady and erosive burning of gunpowder on the development of shot dynamics. For example, the edge ignition of charge consisting of a grained gunpowder for chambers with high elongation encounters some difficulties. At higher charging densities they are caused by the absence of through flow cross section and having significant resistance obstructing for filtration of combustion products in the regions remote from the igniter, that leads to the delay of charge ignition and formation of longitudinal pressure waves, can cause pressing and destruction of the gunpowder elements. Tubular gunpowder is quite reliably ignited by edge igniters, however there are cases when the wrong selection of igniter weighed portion degrades the output characteristics of artillery systems.

Unfortunately, the experimental internal ballistics are not currently meet the requirements of the theory. Wherein with the old problems the development of gas dynamics posed new challenges. In this regard, the important are the data on process parameters such as velocity of flame distribution through the charge, the contribution of the unsteady and erosive effects of the burning velocity, the nature of the movement of gas-gunpowder mixture, regularities of pressure changes at various points in the back space of charge, etc. All these issues require the most careful consideration, because the lack of 
responses to them limits the ability of theoretical approaches for adequate modeling of the shot process.

\section{Main assumptions. System of gas-dynamic equations for igniter period}

In general, we assume that there are three weighed portion of igniter: at the bottom of the channel $\left(\omega_{\mathrm{v} 1}\right)$, between the halves of the charge $\left(\omega_{\mathrm{v} 2}\right)$ and at the bottom of projectile $\left(\omega_{\mathrm{v} 3}\right)$ (see fig. 1). We assume that lower (main) igniter is the first ignited. Additional igniters considered to be ignited as soon as the surface temperature due to convective heat exchange reaches a temperature of igniter. In certain variants additional igniters or one of them may be omitted.

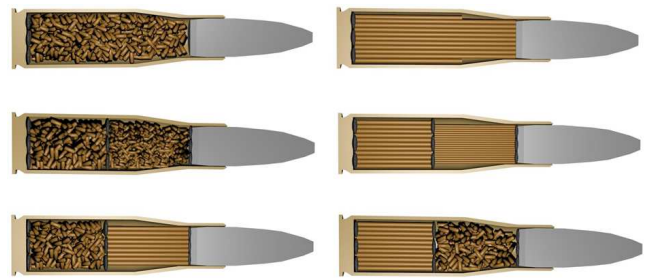

Fig. 1. Charging schemes

For more detailed description of the ignition process we will take into account the air originally present in the firing chamber, and incandescent particles entering the flow with the gaseous products of igniter burning and creating considerable heat flows during deposition on the surface of the gunpowder. We will also consider the difference of thermophysical characteristics of the igniter, the first and second halves of charge. In this case it becomes possible to consider the influence of the brand of igniter composition and more accurately describe the ignition of halves of charge made of different grades of gunpowder.

Combustion products of the first half of charge we shall call the first component of the mixture (denoted by the subscript 1), the second half of charge - the second (2), the air - the third (3), gaseous combustion products of igniter - the fourth (4), heated (glowing) solids in combustion products - the fifth (5).

The size of the particles in the combustion products of black gunpowder was determined experimentally in [1]. Due to their smallness $\left(d_{\mathrm{h}}<1 \mathrm{mc}\right)$ we assumed that velocity and temperature of the particles are equal to the velocity and temperature of the surrounding gases.

In the derivation of the gas-dynamic system of equations describing the gradual ignition, the following assumptions were taken:

1. distances, at which the flow parameters considerably vary, much more than distances between the particles and size of the particles;

2. various phases are present simultaneously at all points of space, at the same time each phase occupies a portion of the mixture; 
3. calculation of movement for each phase can be performed independently from the mixture under the condition that appropriate account of the interaction between the different phases is provided;

4. viscosity and thermal conductivity is significant only in the processes of phases interaction;

5. an average particle size is equal, collisions, i.e. interaction between them can be neglected;

6. movement of phases is one-dimensional;

7. heat transfer to the burning surface of the grains is not taken into account (the velocity of the thermal wave in the gunpowder equals to burning velocity);

8. material of particles is incompressible;

9. parameters of the gas inside and outside of the gunpowder components in this section are identical;

10. combustion products of various parts of the charge, igniter and air are a homogeneous non-reacting mixture with the same velocities, pressures and temperatures;

11. nature of gases for different weighed portions of igniter is the same;

12. grains of igniter move with gunpowder elements;

13. inner and outer surfaces of the powder elements in a given section ignite simultaneously;

14. deposition of incandescent particles in ignited part of the charge is neglected.

The idea for deriving the equations of gas dynamics for igniting period under formulated assumptions is that in conjunction of features of heterogeneous flow [2] it should be considered burning of igniter, the flowing of a multi-component mixture and heat exchange taking into account the deposition of particles on the surface of the ignition. The corresponding one-dimensional system of equations has the form:

$$
\begin{gathered}
\frac{\partial \rho_{i} m S}{\partial t}+\frac{\partial \rho_{i} m S \nu}{\partial x}=S A_{i}, \quad i=\overline{1,5} \\
\frac{\partial \rho m S v}{\partial t}+\frac{\partial \rho m S v^{2}}{\partial x}=-m S \frac{\partial p}{\partial x}-S\left(\tau_{w 1}+\tau_{w 2}\right)+S\left(G_{1}+G_{2}+\sum_{j=1}^{3} G_{\mathrm{v} j}\right) w- \\
-S\left(G_{51}+G_{52}\right) v-\Pi_{\mathrm{c}} \tau_{\mathrm{c}} ; \\
\frac{\partial \rho m S \varepsilon}{\partial t}+\frac{\partial \rho m S \varepsilon v}{\partial x}=-p \frac{\partial[m S v+(1-m) S w]}{\partial x}+S\left(\tau_{w 1}+\tau_{w 2}\right)(v-w)+ \\
+S G_{1}\left[Q_{1}+\frac{(v-w)^{2}}{2}\right]+S G_{2}\left[Q_{2}+\frac{(v-w)^{2}}{2}\right]+\sum_{j=1}^{3} S G_{\mathrm{v} j}\left[Q_{\mathrm{v} j}+\frac{(v-w)^{2}}{2}\right]- \\
-S\left(q_{\mathrm{T} 1}+q_{\mathrm{T} 2}\right)+\Pi_{\mathrm{c}} \tau_{\mathrm{c}} v-\Pi_{\mathrm{c}} q_{\mathrm{c}} ;
\end{gathered}
$$




$$
p\left(1-\alpha \rho_{\mathrm{g}}\right)=\theta \rho \varepsilon
$$

where

$$
A_{i}=\left\{\begin{array}{c}
G_{1}, i=1 ; \\
G_{2}, i=2 ; \\
0, i=3 ; \\
\sum_{j=1}^{3} \xi_{0} G_{\mathrm{v} j}, i=4 ; \\
\sum_{j=1}^{3}\left(1-\xi_{0}\right) G_{\mathrm{v} j}-G_{51}-G_{52}, i=5 .
\end{array}\right.
$$

The equations of movement and continuity of the solid phase for tubular and grained gunpowder components are recorded separately.

For flow region occupied by grained gunpowder, it must be written

$$
\begin{gathered}
\frac{\partial a_{j} S}{\partial t}+\frac{\partial a_{j} S v}{\partial x}=0 \\
\frac{\partial \delta_{j}(1-m) S w}{\partial t}+\frac{\partial \delta_{j}(1-m) S w^{2}}{\partial x}=-(1-m) S \frac{\partial p}{\partial x}-S G_{j} w+S \tau_{w_{j}} .
\end{gathered}
$$

The index $j$ in the equation (2) is saved with a view to emphasize that they are solved separately for each half of charge. Accordingly, for the region occupied by the tubular gunpowder, we have

$$
\begin{gathered}
n_{j}=\text { const }, \\
\left(1-\bar{\psi}_{j}\right) \omega_{j} \frac{\partial w}{\partial t}=[(1-m) S]_{0} p_{0}-[(1-m) S]_{L} p_{L}+\int_{0}^{L_{0 j}}\left[p \frac{\partial(1-m) S}{\partial x}+S \tau_{w j}\right] d x,
\end{gathered}
$$

which in this case must be supplemented by physical constraints, taking into account limit gravimetric charging density for the grained gunpowders at each point of volume and the possibility of movement of gunpowder tubes under conditions where the projectile has not gained sufficient speed.

The burning equation for the gunpowder elements after ignition has the form:

$$
\frac{\partial \psi_{j}}{\partial t}+w \frac{\partial \psi_{j}}{\partial x}=\frac{S_{0 j}}{\Lambda_{0 j}} \sigma_{j}\left(\psi_{j}\right) u_{k j}=\frac{\kappa_{p j}}{e_{1 j}} \sigma_{j}\left(\psi_{j}\right) u_{k j}
$$

Equation for the burning of igniter is taken in the form:

$$
\frac{\partial \psi_{\mathrm{v} j}}{\partial t}+w \frac{\partial \psi_{\mathrm{v} j}}{\partial x}=\frac{d \psi_{\mathrm{v} j}}{d t}=A_{0 j} f\left(\psi_{\mathrm{v} j}\right) p^{\nu_{\mathrm{v} j}},(j=\overline{1,3}) .
$$

Here we have introduced the following notations: $t$ - time; $x$ - longitudinal coordinate; $\rho_{i}$ - the density of the respective components of the mixture $(i=\overline{1,5}) ; \rho=\sum_{i=1}^{5} \rho_{i}-$ total density of the mixture; $\rho_{\mathrm{g}}=\sum_{i=1}^{4} \rho_{i}$ - total density of the gases; $m$ - porosity of the mixture (volume of voids per unit volume); $S$ - variable cross-sectional area of the barrel or chamber; $v, w$ - velocities of gas and solid phase in the barrel respectively; $p$ - pressure of gunpowder gases; $\tau_{w 1}, \tau_{w 2}$ - hydraulic resistance of the upper and lower parts of the 
gunpowder components in a unit volume; $G_{1}, G_{2}$ - gas arrival for top and bottom parts of gunpowder elements per unit volume; $G_{5 j}, q_{\mathrm{T} j}$ - mass velocity of deposition of particles and heat flow on the ignition surface $(j=1,2) ; \Pi_{\mathrm{c}}$ - variable cross section perimeter of camera or barrel; $\tau_{\mathrm{c}}$ - the friction force of the gunpowder elements on the barrel per unit area; $\varepsilon=\frac{1}{\rho} \sum_{i=1}^{5} \rho_{i} c_{i} T$ - internal energy per unit mass of the mixture; $T$ - temperature of the gas mixture; $c_{i}$ - heat capacity of the gaseous components at a constant volume $(i=\overline{1,4})$ and solid particles in the burning products of igniter $(i=5) ; Q_{1}, Q_{2}$ - heating value (potential) of the lower and upper parts of gunpowder elements; $q_{\mathrm{c}}$ - heat flow on the barrel surface; $\alpha$ - covolume; $\theta=k-1 ; k=\frac{c_{p}}{c_{v}}-$ adiabatic index; $c_{v}, c_{p}$ - gas heat capacity at constant volume and pressure, respectively; $\xi_{0}$ - the mass fraction of the gas phase entering the flow as a result of igniter burning; $a$-calculating concentration of grained gunpowder elements (subscript $j$ is omitted); $\delta$ - the density of the gunpowder components; $n$ - the number of elements in the beam of tubular gunpowder; $\omega$ - mass of gunpowder; $L_{0}$ - length of gunpowder tubes (subscript "0" refers to the left edge of tubes, " $L "$ - to the right edge); $\Lambda_{0}, S_{0}$ - initial volume and the surface of the gunpowder grain; $\psi$ - the relative share of burnt gunpowder; $\bar{\psi}$ - average relative share of burnt gunpowder in the tubular charge; $\psi_{\mathrm{v}}$ - the relative share of burnt igniter; $\sigma(\psi)$ - ratio of the current combustion surface of gunpowder grains to the original; $\kappa_{p}$ - form factor of gunpowder element; $2 e_{1}$ - initial thickness of the burning body of gunpowder component; $u_{k}$ - linear velocity of the gunpowder burning; $f\left(\psi_{\mathrm{v}}\right)$ - Charbonnier function for grains of igniter; $A_{0}, \nu_{\mathrm{v}}$ - law constants for velocity of igniter burning; $G_{\mathrm{v}}$ - the arrival of the combustion products from the surface of the igniter in a unit volume per second:

$$
G_{\mathrm{v}}=\frac{\omega_{\mathrm{v}}}{S \Delta x_{\mathrm{v}}} A_{0} f\left(\psi_{\mathrm{v}}\right) p^{\nu_{\mathrm{v}}}
$$

$\omega_{\mathrm{v}}-$ mass of igniter; $\Delta x_{\mathrm{v}}$ - the distance at which the corresponding igniter is concentrated; $Q_{\mathrm{v}}$ - heat capacity of igniter:

$$
Q_{\mathrm{v}}=\frac{f_{\mathrm{v}}}{k_{4}-1}+\left(1-\xi_{0}\right) c_{5} T_{\mathrm{v} v}
$$

$f_{\mathrm{v}}=\xi_{0} R_{4} T_{\mathrm{v} v}$ - force of igniter gunpowder; $R_{i}-$ gas constants for the components $(i=\overline{1,4}) ; T_{\mathrm{v} v}$ - combustion temperature of igniter at constant volume; $k_{4}$ - adiabatic index for gaseous products of igniter burning.

Coefficients of dynamic viscosity and thermal conductivity of the mixture are defined by the relations [3]:

$$
\begin{gathered}
\mu=\left(\sum_{i=1}^{4} \frac{\rho_{i}}{\rho_{\mathrm{g}} \mu_{i}}\right)^{-1} ; \\
\lambda=0,5\left[\sum_{i=1}^{4} \lambda_{i} \frac{\rho_{i} R_{i}}{\rho_{\mathrm{g}} R_{\mathrm{g}}}+\left(\sum_{i=1}^{4} \frac{\rho_{i} R_{\mathrm{i}}}{\rho_{\mathrm{g}} R_{\mathrm{g}} \lambda_{i}}\right)^{-1}\right],
\end{gathered}
$$

where

$$
R_{\mathrm{g}}=\sum_{i=1}^{4} \frac{\rho_{i} R_{i}}{\rho_{\mathrm{g}}}
$$


In this case the value $\theta$ is determined by the expression:

$$
\theta=\frac{\sum_{i=1}^{4} \rho_{i} R_{i}}{\sum_{i=1}^{5} \rho_{i} c_{i}} .
$$

Covolume of combustion products begins to manifest itself at high pressures, when the concentration of air and combustion products of igniter is negligible, and therefore to determine the current value of $\alpha$ we can use the formula

$$
\alpha=\frac{\alpha_{1} \rho_{1}+\alpha_{2} \rho_{2}}{\rho}
$$

where $\alpha_{1}, \alpha_{2}$ - covolume of combustion products of the first and second halves of the charge respectively.

For a known linear burning velocity of gunpowder $\left(u_{k}\right)$ gas coming from the surface of the grained gunpowder per unit volume is determined from the expression

$$
G=a S_{0} \sigma(\psi) \delta u_{k}
$$

Hydraulic resistance recorded from the representation of flow for set of elements is determined by the relation $[4,5]$ :

$$
\tau_{w}=\lambda_{w} \frac{\rho(v-w)|v-w|}{2} a \frac{\pi d_{\Lambda \sigma}^{2}}{4} f
$$

where $\lambda_{w}$ - coefficient of resistance of the gunpowder grain in the layer; $f=\frac{d_{S \sigma}^{2}}{d_{\Lambda \sigma}^{2}}-$ correction for non-sphericity of the particles; $d_{\Lambda \sigma}, d_{S \sigma}$ - diameter of spheres that are equivalent to the grained gunpowder element at the current volume limiting of its $\left(\Lambda_{\sigma}\right)$ and current limiting surface $\left(S_{\sigma}\right)$ respectively.

Tightness and flow regime for set of particles is taken into account in the expression for the coefficient of resistance:

$$
\lambda_{w}=\lambda_{w}\left(m, \operatorname{Re}_{\sigma}\right) \text { или } \lambda_{w}=\lambda_{w}\left(m, \operatorname{Re}_{\mathrm{e}}\right),
$$

where $\operatorname{Re}_{\sigma}=\frac{\rho|v-w| d_{S \sigma}}{\mu}-$ Reynolds number for the particle; $\operatorname{Re}_{\mathrm{e}}=\frac{4 \rho|v-w| m}{\mu a S_{\sigma}}-$ equivalent Reynolds number for backfill of grained gunpowder.

In general, in the expressions (11) and (12) it is necessary to make adjustments associated with the internal porosity of the gunpowder particles. Obviously, such amendment would be so smaller, that the ratio of internal porosity to the porosity of the mixture is smaller. For artillery systems at all times during the shot, this ratio is

$$
\frac{m_{\text {in }}}{m}=0.03 \div 0.10
$$

where $m_{\text {in }}$ - an internal void volume of particles in unit volume. Below the influence of the internal porosity on the resistance of particles will be neglected.

Based on the structure of the formula for the resistance coefficient of the particles

$$
\lambda_{w}=\frac{c^{\prime}}{\mathrm{Re}_{\mathrm{e}}}+c^{\prime \prime}, c^{\prime} \sim 10^{2}, c^{\prime \prime} \sim 10^{0}
$$


it can be concluded that at high $\operatorname{Re}_{\mathrm{e}} \approx \operatorname{Re}_{\sigma}$ (usually $\mathrm{Re}_{\sigma}=10^{4} \div 10^{6}$ ) the first term describing the interaction due to the frictional forces, is small in comparison with the second term characterizing the resistance of particle. For this reason, blowing of the gunpowder gases, which affects mainly on the surface friction, effects slightly on the total resistance of the gunpowder grains for the incoming flow. Experimentally, this fact was confirmed in $[6,7]$, where it is shown that since $\operatorname{Re}_{\sigma}>10^{3}$ correction for blowing can be ignored.

According to [8], good generalizability of the experimental data on the resistance of the layer of particles with any form occurs if in the expression (12) as determinative the maximum $\left(v_{m}-w\right)$ flow velocity of set of particles was chosen but not mean $(v-w)$, which are related by

$$
m\left(v_{m}-w\right)=\psi_{m}\left(v_{m}-w\right),
$$

where $\psi_{m}=1-1.17(1-m)^{2 / 3}$, then

$$
\tau_{w}=\zeta \frac{\rho(v-w)|v-w| m^{2}}{2 \psi_{m}^{2}} a \frac{\pi d_{\Lambda \sigma}^{2}}{4} .
$$

At $\operatorname{Re}_{\sigma}>10^{4}$ it can be taken $[8] \zeta=0.5 \mathrm{~m}$.

We will also take into account the particle flow crisis, which occurs at $\operatorname{Re}_{\sigma}>3 \cdot 10^{5}$; in this case $\zeta=0.1[4]$.

Standard seven-channel gunpowder grain splits on 12 elements. In the calculation of the resistance force, we assume that the average size of the elements in the decay is the same and in the phase of decay they move by single "package". Then the expression for the resistance force (14) does not change, if the $a$ means concentration of the "packages and the current value $d_{\Lambda \sigma}$ to determine through the surface of all its elements. The Reynolds number of the elements in this case will be determined by the formula

$$
\operatorname{Re}_{\sigma}=\frac{\rho(v-w)}{\mu} \frac{d_{\Lambda \sigma}}{\sqrt{12}}
$$

Interaction functions, the right-hand side of equations (1), are discontinuous functions of the spatial coordinate and time. Points of discontinuity along the coordinate are determined by the initial location of the gunpowder elements and igniters, composing the missile charge, as well as the laws of their subsequent motion. Discontinuous of function on the time associated with ignition and the end of the burning charge is recorded in a known manner by means of the Heaviside function

$$
e(t)=\left\{\begin{array}{l}
1, \text { если } t>0 ; \\
0, \text { если } t \leq 0 .
\end{array}\right.
$$

Gas coming from the surface of tubular charge is determined by perimeter of the combustion $\Pi=n \pi\left(d_{0}+D_{0}\right)$ :

$$
S G=\Pi \delta u_{k} .
$$

Therein $d_{0}$ - initial inner diameter of the gunpowder tube; $D_{0}$ - initial outer diameter of the gunpowder tube.

For the tubular powders the interaction force is due only to surface friction and, after adjustment for blowing $\left(\varepsilon_{B}\right)$ and hydrodynamic stabilization of the flow $\left(\varepsilon_{L}\right)$, adopted in the form

$$
S \tau_{w}=\Pi \frac{\xi}{8} \rho(v-w)|v-w| \varepsilon_{B} \varepsilon_{L} .
$$


At $\operatorname{Re}_{\Pi}<10^{5}$ the resistance coefficient determined by the formula of Blasius

$$
\xi=\frac{0.316}{\operatorname{Re}_{\Pi}^{0.25}}
$$

where $\operatorname{Re}_{\Pi}=\frac{4 \rho|v-w| m S}{\mu \Pi}-$ Reynolds number for the tubular charge. At $\operatorname{Re}_{\Pi}>10^{5}-$ by the formula Nikuradze [3]

$$
\xi=0.00332+\frac{0.221}{\operatorname{Re}_{\Pi}^{0.237}}
$$

According to [9], the correction for blowing is determined by the relation

$$
\varepsilon_{B}=\frac{B}{\exp (B)-1}
$$

where $B=\frac{8 \delta u_{k}}{\rho|v-w| \xi}$ - parameter of blowing. Using the Reynolds analogy, the expression for $\varepsilon_{L}$ we are written in the form [10]:

$$
\varepsilon_{L}=1.38\left(\frac{x}{d_{\Pi}}\right)^{-0.12}
$$

where $d_{\Pi}=\frac{4 m S}{\Pi}-$ given diameter of the tubular charge.

In the context of our problem the formula (16) has an approximate character, nevertheless further clarification is meaningless, because the force of viscous resistance for the burning tubular gunpowders, as shown by calculations, much less than the force caused by the pressure gradient, and it can be neglected.

To close obtained system of equations it is necessary to determine the deposition velocity for incandescent particles and the heat flow to the surface of grained and tubular powders. In discussing about appropriate dependencies index $i$ will be omitted.

The mass of particles captured per unit time by the all gunpowder grains being in a unit volume is:

$$
G_{5}=\rho_{5}|v-w| E_{0} a \frac{\pi d_{\Lambda \sigma}^{2}}{4}\left[1-e\left(t-t_{\mathrm{z}}\right)\right]
$$

where $E_{0}$ - deposition efficiency, equal to the fraction of settled particles from the flying to the obstacle; $t_{\mathrm{z}}$ - ignition time for corresponding point of the charge.

The main mechanism of particles deposition on the surface of the streamlined bodies at high flow velocities is the inertial mechanism. As a first approximation for the deposition efficiency we will use the data of [11], where for large values of Reynolds numbers $\left(\operatorname{Re}_{\sigma}\right)$ it is recommended the relationship:

$$
E_{0}=\frac{l^{2}}{(l+0.5)^{2}}, l=\frac{\delta_{\mathrm{h}}}{9 d_{\Lambda \sigma}} d_{\mathrm{h}}^{2} \frac{|v-w|}{\mu},
$$

where $\delta_{\mathrm{h}}$ - material density of incandescent particles.

The main mechanism of particles deposition on the channel walls of the gunpowder tube is deposition due to turbulent fluctuations. For tubular powders the deposition velocity is determined from the expression

$$
S G_{5}=\Pi K_{0} \rho_{5}|v-w|\left[1-e\left(t-t_{\mathrm{z}}\right)\right]
$$


The dependence for the coefficient of the particles deposition in the formula (19) for the turbulent flow regime, according to [12], is adopted as

$$
K_{0}=\frac{\xi}{8}
$$

In determining the total heat flow from the combustion products to the surface of the gunpowder the heat transfer coefficient is based on the principle of separation for components of heat exchange:

$$
\alpha=\alpha_{\mathrm{konv}}+\alpha_{\mathrm{kont}}+\alpha_{\mathrm{luch}}
$$

where $\alpha_{\text {konv }}$ - convective component of heat exchange; $\alpha_{\text {kont }}$ - contact component of heat exchange; $\alpha_{\text {luch }}$ - radiant component of heat exchange.

Assuming that the settled particles are uniformly distributed on the outer bounding surface of the powder grains, and, assuming that during the deposition, they cool down to a surface temperature, we have

$$
\alpha_{\mathrm{kont}}=c_{5} \frac{G_{5}}{a S_{\sigma}}
$$

Using the dependence of the heat exchange coefficient for pure gas [13] for the grain powders it can be written

$$
\alpha_{\mathrm{T}}=\frac{0,61 \lambda \mathrm{Re}_{\mathrm{T}}^{0,67}}{\sqrt{S_{\sigma}}}+c_{5} \frac{G_{5}}{a S_{\sigma}}+\varepsilon_{s} \varepsilon_{\mathrm{p}} \sigma_{0}\left(T^{2}+T_{s}^{2}\right)\left(T+T_{s}\right),
$$

where $\operatorname{Re}_{\mathrm{T}}=\frac{\rho_{\mathrm{g}}|v-w| m \sqrt{S_{\sigma}}}{\mu} ; \sigma_{0}$ - Stefan-Boltzmann constant; $T_{s}$ - surface temperature of the gunpowder. According to the literature degree of blackness surface charge, covered with a layer of sediment, is $\varepsilon_{s}=0.8 \div 0.9$, and the effective degree of blackness for the flow of the combustion products of black powder $-\varepsilon_{\mathrm{p}}=0.25 \div 0.30$.

The intensity of heat exchange per unit volume is determined by the formula

$$
q_{\mathrm{T}}=a S_{\sigma} \alpha_{\mathrm{T}}\left(T-T_{s}\right)\left[1-e\left(t-t_{\mathrm{z}}\right)\right] .
$$

For tubular powders $\alpha_{\text {kont }}$ must be determined from the expression

$$
\alpha_{\mathrm{kont}}=c_{5} \frac{S G_{5}}{\Pi} .
$$

For the convective component we will take [10]

$$
\alpha_{\mathrm{konv}}=\frac{0.023 \lambda}{d_{\Pi}} \operatorname{Re}_{\Pi}^{0.8} \operatorname{Pr}^{0.43} \varepsilon_{L},
$$

where the Prandtl number is equal to $\operatorname{Pr}=\mu c_{p} / \lambda$.

Heat exchange with the surface of the tubular charge is calculated by the formula

$$
S q_{\mathrm{T}}=\Pi \alpha_{\mathrm{T}}\left(T-T_{s}\right)\left[1-e\left(t-t_{\mathrm{z}}\right)\right] .
$$

Heat exchange and friction of a heterogeneous mixture with the surface of the channel have the complex nature. Analysis of existing works shows that studies on heat exchange in 
the barrel are based on the conception of convective heat exchange at the flow of pure gas in the tubes, whose averaged parameters are determined from the solution of the problem of internal ballistics. This approach is completely abstracted from the two-phase nature of the flow of gas-powder mixture and its influence on the development of the boundary layer. Wherein relations of semi-empirical theory of turbulence obtained for single-phase flow are considered valid for a two-phase mixture in the barrel. Interaction of the solid phase with the surface of the channel is not considered. Nevertheless, the developed approaches lead to good agreement with experimental data.

Since the share of friction and heat exchange to the surface of the barrel in the overall balance of quantity of motion and energy of the shot is small, we will use a simple approximate relationships, neglecting the contact heat exchange and friction of the particles on the barrel, the more that any information about these processes for particles with not spherical form is absent in the literature.

Thus,

$$
\begin{gathered}
q_{\mathrm{c}}=\mathrm{Nu} \frac{\lambda}{d_{\mathrm{kn}}}\left(T-T_{\mathrm{c}}\right), \\
\tau_{\mathrm{c}}=\frac{\xi}{8} \rho v|v|,
\end{gathered}
$$

where $T_{\mathrm{c}}$ - the surface temperature of the barrel; $d_{\mathrm{kn}}-$ a variable diameter of camera or barrel. According to [14], the relation for the Nusselt number takes the form

$$
\mathrm{Nu}=0.023 \operatorname{Re}^{0.8} \operatorname{Pr}^{0.4}
$$

Reynolds number is defined by the formula

$$
\operatorname{Re}=\frac{\rho|v| d_{\mathrm{kn}}}{\mu}
$$

Variable surface temperature of the barrel $\left(T_{\mathrm{c}}\right)$ is determined by the known approximate method of R.E. Sorkin [15]:

$$
\frac{d \eta}{d t}=\frac{2 \mathrm{Nu}^{2} \lambda^{2}}{d_{\mathrm{kn}}^{2} c_{\mathrm{c}} \delta_{\mathrm{c}} \lambda_{\mathrm{c}}}\left(T-T_{\mathrm{n}}-\sqrt{\eta}\right)^{2}, \sqrt{\eta(t)}=T_{\mathrm{c}}-T_{\mathrm{n}}, \eta(0)=0,
$$

where $c_{\mathrm{c}}, \delta_{\mathrm{c}}, \lambda_{\mathrm{c}}$ - heat capacity, density and thermal conductivity of the barrel; $T_{\mathrm{n}}-$ initial temperature of the barrel.

As the initial conditions of the system (1) we define the atmospheric conditions and the conditions of rest. Thus we have:

$$
\begin{aligned}
& \text { at } t=0,0 \leq x \leq L_{\mathrm{km}}, \\
& \qquad \begin{array}{c}
v=0, p=98100 \mathrm{~Pa}, T=T_{\mathrm{n}}, \rho_{1}=\rho_{2}=\rho_{4}=\rho_{5}=0, \\
\rho_{3}=\frac{98100}{R_{3} T_{\mathrm{n}}}, \psi_{1}=\psi_{2}=0, \psi_{\mathrm{v} j}=0(j=\overline{1,3})
\end{array}
\end{aligned}
$$

where $L_{\mathrm{km}}$ is the length of the camera.

Boundary conditions: at $x=0, t \geq 0$,

$$
v=0
$$


in case when lower half of charge is made of grained powder $w=0$;

at $x=x_{\mathrm{cn}}, t \geq 0$,

$$
v=v_{\mathrm{cn}} ; q \frac{d v_{\mathrm{cn}}}{d t}=S_{\mathrm{cn}}\left(p-p_{\mathrm{pr}}\right)
$$

where $x_{\mathrm{cn}}, v_{\mathrm{cn}}, S_{\mathrm{cn}}, q$ - position, velocity, cross-sectional area and mass of the projectile, respectively; $p_{\mathrm{cn}}$ - the pressure at the bottom of the projectile;

Backpressure $p_{\mathrm{pr}}$ is determined with sufficient accuracy by solving the problem of movement of the piston in the tube with a constant velocity as the pressure behind a detached shock wave [16]:

$$
p_{\mathrm{pr}}=p_{\mathrm{n}}\left(1+\frac{k(k+1)}{4} \frac{v_{\mathrm{cn}}^{2}}{c_{\mathrm{v}}^{2}}+\frac{k v_{\mathrm{cn}}}{c_{\mathrm{v}}} \sqrt{1+\frac{(k+1)^{2} v_{\mathrm{cn}}^{2}}{16 c_{\mathrm{v}}^{2}}}\right) .
$$

Here $p_{\mathrm{n}}$ - initial air pressure in the barrel; $c_{\mathrm{v}}=\sqrt{k_{\mathrm{v}} p_{\mathrm{v}} / \rho_{\mathrm{v}}}-$ sound velocity in air; $k_{\mathrm{v}}, p_{\mathrm{v}}$, $\rho_{\mathrm{v}}$ - adiabatic index, pressure, and density of the air ahead the shock wave, respectively.

\section{Formulation of conjugated problems of gas dynamics and heat and mass exchange}

Creation of modern design methodologies for missile charges of artillery systems is caused by a further development of mathematical modeling for the process of shot associated with detailing of intrachamber processes that is based on solutions of conjugated problems of gas dynamics, heat and mass exchange of unsteady and erosive burning of components for missile charge.

For the conditions of the shot it should identify the following factors affecting the burning:

- powder elements are in conditions of strong blowing $(v-w)$, reaching $1000 \mathrm{~m} / \mathrm{s}$;

- the change of ballistic parameters is abruptly unsteady, wherein the development of the process dynamics depends on the conditions of ignition;

- for tubular gunpowders with large elongation the conditions of uneven burning are valid;

- at burning of grained powder it is necessary to consider the hydrodynamics of flow inherent for the fluidized layer.

Physical basis and mechanism of non-stationary burning velocity of gunpowder were discovered in the works Ya.B. Zel'dovich $[17,18]$, where it is shown, that unsteady burning in transition mode is determined by the relation of the relaxation times of the condensed phase ( $k$-phase) and parameters of the studied process, influencing on the burning velocity. Development of this work are the works of B.V. Novozhilov [19], B.T. Erokhin [20] and other Researchers.

Currently there are a large number of works devoted to the theory of erosive burning of gunpowder (see the works of Ya.B. Zel'dovich [21], J. Korner [22], J. Vandenkerkhove [23], M.T. Vilyunov [24], B.T. Erokhin [20]). The basis of all above works is the asymptotic solution of equations of heat conduction and diffusion in the gas phase of the burning 
gunpowder. In this case different approximations of semiempirical theory of turbulence are involving for the circuit of equations in viewpoint of defining the turbulent terms of transport coefficients.

The basis of other areas of theoretical research on erosive burning laid by J. Lenoir, J. Robilliard [25] and G.K. Karakozov [26]. In their view, the erosion effect is caused by the increase of the heat flow to the surface of gunpowder due to additional convective component. In $[25,26]$ it is supposed, that total burning velocity consists of two parts: the velocity depending on the initial temperature and pressure, and erosion additives, proportional to the velocity of convective heat transfer to the fuel surface.

It should be noted that from the point of view of practical applications, all of these studies focused on the conditions typical for the work of solid propellant rocket motors (SPRM). Attempts to extend them to the high pressures typical for artillery guns were not undertaken. Here we can only note the experimental work of V.P. Nelaev [27], where he studied the erosive burning of ballistic fuels up to pressure $100 \mathrm{MPa}$.

Analysis of the literature also shows that all studies on the erosive burning refer to simple flows (channel, plate), for heterogeneous environments (granular fuels or grained gunpowders) any data in the literature is absent.

For artillery guns accounting of erosive burning was not performed.

Fig. 2 shows the change of gas-dynamic parameters for the middle part of gunpowder tube of lower half of charge for $100 \mathrm{~mm}$ antitank gun from the ignition moment of given point of charge. The problem is solved without taking into account the effects of unsteady and erosive burning of gunpowder. Evaluation of erosive effect by the formula [28]

$$
\varepsilon=1+0.05(J-8)
$$

fair in the range $5 \leq p \leq 20 \mathrm{MPa}(J-$ parameter of V.N. Vilyunov), shows, that at least immediately after ignition the burning velocity of gunpowder can be increased by 3-4 times.

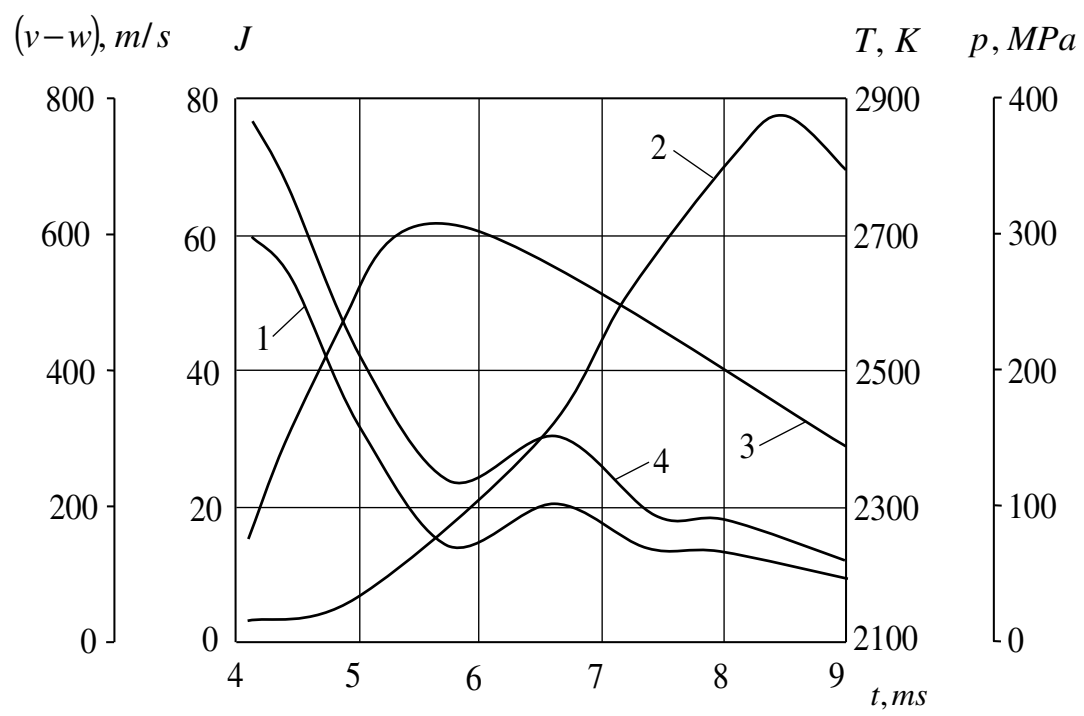

Fig. 2. Change of flow parameters in the process of shooting: $1-(v-w) ; 2-p ; 3-T ; 4-J$ 
Comparison of typical times at different pressures is shown in Fig. 3. It turns out that at low pressures typical for ignition,

$$
t_{k} \geq t_{\mathrm{a}}, t_{\mathrm{g}}<<t_{\mathrm{a}}
$$

where $t_{k}, t_{\mathrm{g}}$ - relaxation time for the condensed and gas phase of powder combustion zone respectively; $t_{\mathrm{a}}$ - the typical time of the shot. At medium and high pressures

$$
t_{k}<<t_{\mathrm{a}}, t_{\mathrm{g}} \leq t_{k}
$$

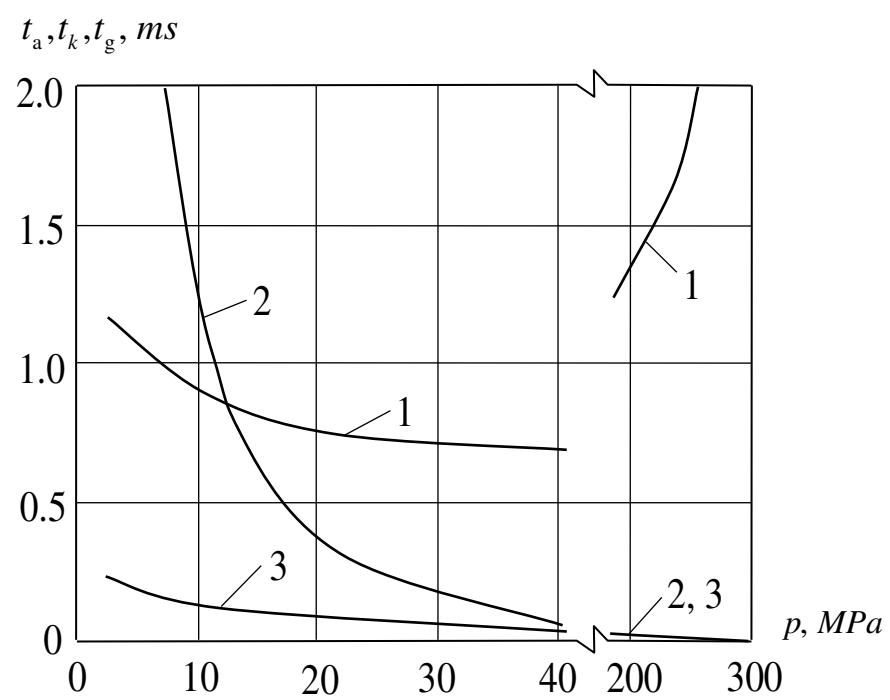

Fig. 3. A comparison of the typical times during the shot: $1-t_{\mathrm{a}} ; 2-t_{k} ; 3-t_{\mathrm{g}}$

Thus, with respect to the typical relaxation time of the shot relaxation time of the gas phase is negligible, so that the problem of combustion in the gas phase from the beginning may be regarded as stationary. In $k$-phase you must first solve unsteady equations. However, the non-stationary component of the burning velocity, caused by inertia of $k$-phase, with increasing pressure decays rapidly and after inequalities start

$$
t_{k}<<t_{\mathrm{a}}, t-t_{\mathrm{z}}>t_{p}
$$

where $t_{p}=2 t_{k}+2 \sqrt{t_{k}^{2}+t_{\mathrm{z}} t_{k}}$ - burnout time of the heated layer formed over a period of ignition $\left(t_{\mathrm{z}}\right)$, at the corresponding point of the charge you can move to a stationary formulation of the problem.

The estimates presented show that the erosive and non-stationary effects reveal itself maximally in the initial stage of the shot.

The process of heating and burning of $k$-phase is considered within the local solid-phase model of Merzhanov A.G., Dubovitskiy F.I. [29].

Under the assumption of "0th reaction order and constancy of the thermophysical parameters of $k$-phase, and taking into account, that temperature gradient in the interior 
of the powder is much greater than the gradient along the axis $x$, the system of equations describing the process of unsteady heating and subsequent burning of gunpowder for the solid-phase model has the form

$$
\frac{\partial T_{k}}{\partial t}=\kappa_{k} \frac{\partial^{2} T_{k}}{\partial y_{k}^{2}}+u_{k} \frac{\partial T_{k}}{\partial y_{k}}+\frac{Q_{k}}{c_{k}} \Phi_{k}\left(T_{k}\right), \quad \frac{\partial \beta}{\partial t}=u_{k} \frac{\partial \beta}{\partial y_{k}}+\Phi_{k}\left(T_{k}\right),
$$

where $\Phi_{k}\left(T_{k}\right)=Z_{k} \exp \left(-\frac{E_{k}}{R_{0} T_{k}}\right) ; R_{0}$ - universal gas constant; $y_{k}$ - coordinate directed into the interior of the powder; $T_{k}, \beta, \kappa_{k}$-temperature, depth of conversion and thermal diffusivity of $k$-phase respectively; $Z_{k}, E_{k}, Q_{k}, c_{k}$ - pre-exponential factor, activation energy, thermal effect of reaction and the heat capacity of $k$-phase respectively.

Equations (39) are written in the coordinate system associated with the surface of the powder; it must be put $u_{k}=0$ before ignition.

The conventional burning condition at the present time does not exist. In the general case the burning condition is implied the relationship between temperature, concentration on the surface, their derivatives and pressure:

$$
F\left(T_{s}, \beta_{s},\left.\frac{\partial T_{k}}{\partial y_{k}}\right|_{y_{k}=0},\left.\frac{\partial \beta}{\partial y_{k}}\right|_{y_{k}=0}, p\right)=0,
$$

which finally must be established experimentally. Here $T_{s}, \beta_{s}$ - temperature and conversion depth of $k$-phase at the burning surface, respectively.

In the classical works [29-31], the burning condition is taken in the form:

$$
\beta_{s}=\beta_{*}=1 \text {. }
$$

Upon dispersion $\beta_{*}<1$. Naturally this condition must be chosen as the criterion of ignition, then heating, ignition and subsequent powder burning will be described by the same system of equations.

Before ignition initial and boundary conditions of the system (39) have the form: at $t=0, y_{k} \geq 0$

$$
T_{k}=T_{\mathrm{n}}, \beta=0
$$

at $y_{k}=0, t \geq 0$

$$
-\lambda_{k} \frac{\partial T_{k}}{\partial y_{k}}=\alpha_{\mathrm{T}}\left(T_{\mathrm{p}}-T_{s}\right), \beta<\beta_{*}
$$

at $y_{k} \geq \infty, t \geq 0$

$$
T_{k}=T_{\mathrm{n}}\left(\frac{\partial T_{k}}{\partial y_{k}}=0\right), \beta=0\left(\frac{\partial \beta}{\partial y_{k}}=0\right) .
$$

After ignition on the burning surface you need to write: at $y_{k} \geq \infty, t \geq 0$

$$
q_{k}=q_{s}-\left(c_{p}-c_{k}\right) m_{k} T_{s}-p m_{k}\left(\alpha-\frac{1}{\delta}\right), T_{k}=T=T_{s},
$$

where $q_{k}=-\left.\lambda_{k} \frac{\partial T_{k}}{\partial y_{k}}\right|_{s}, q_{s}=\left.\lambda \frac{\partial T}{\partial y}\right|_{s} ; T_{\mathrm{p}}$ - flow temperature of the combustion products; $\lambda_{k}$ - the thermal conductivity coefficient of $k$-phase; $m_{k}=\delta u_{k}$. 
In accordance with the ideas developed in [25, 26], we assume, that total heat flow from the gases to the surface of the powder in the case of unsteady erosive burning is made of the thermal flow $q_{p}$, that would occur in the absence of the flow of gases, and from the convective $q_{v}$. The last component forms the erosion supplement to non-stationary burning velocity of gunpowder.

Since the subsequent (after ignition) non-stationary burning of gunpowder in the chamber of guns occurs in conditions of intensive blowing by the igniter gases, the share of the heat flow $q_{p}$ decreases in the total balance of heat coming. Calculations show that in this period $q_{p} \approx q_{p}^{0}<<q_{v}$ (here $q_{p}^{0}$ - heat flow forming a normal stationary burning velocity), but then the influence of possible fluctuations of value $q_{p}$ on the formation of a non-stationary burning velocity will also decrease. As the pressure increases $q_{p}$ becomes comparable with $q_{v}$, but unsteadiness of $k$-phase degenerates and $q_{p} \rightarrow q_{p}^{0}$. That is, under conditions typical for barrel systems, the influence of the gas phase to the burning velocity in the general case can be reduced to the statement of the approximate boundary condition

$$
\left.\lambda \frac{\partial T}{\partial y}\right|_{s}=q_{p}^{0}+q_{v}
$$

where the expression for $q_{v}$ и $q_{p}^{0}$ is determined from the dependencies are known from scientific sources.

This approximate approach will be used for cylindrical channels and the channels formed by the outer surfaces of the tubes, centered in the beam (see fig. 4). The change in the formula (43) will apply only to the law of heat exchange, which is determined by the channel configuration, therefore in determining the $q_{v}$ as typical size here is a channel diameter, if burning is seen in the channel, or equivalent effective diameter, if burning is seen in the gap.

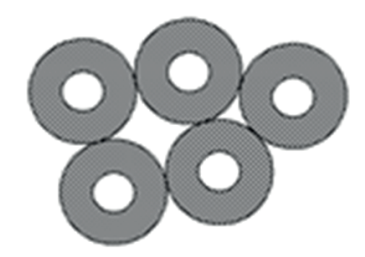

Fig. 4. The beam of tubular gunpowder

Testing of obtained expressions was performed on known experimental data and calculated data, obtained in a more precise original formulation of the problem in the border-layer approximation. Generally, there was a satisfactory agreement between the results in a wide range of external factors.

\section{Conclusion}

In conclusion, we note that building of any complete theory for erosive burning of finely dispersed gunpowders is currently not possible because of the lack of direct experimental data. One thing is clear, the outer surface of the grains in the shooting conditions is exposed to intensive blowing by turbulent high-temperature flow. To determine the erosive burning within the theory of Ya.B. Zel'dovich - J. Korner - V.N. Vilyunov [21-24] it is necessary 
to know the change in the characteristics of turbulence along the normal from the surface of the powder grain. This problem is unlikely to be solved for such a complex area as the filling the grained gunpowder. In these circumstances, apparently, easier methodologically to solve the problem from the position of already used approach of J. Lenoir, J. Robilliard, G.K.Karakozov [25, 26], considering the hydrodynamics of flow in the filling of grained gunpowder like the flow in rough channels (see fig. 5) with the corresponding heat exchange coefficient.
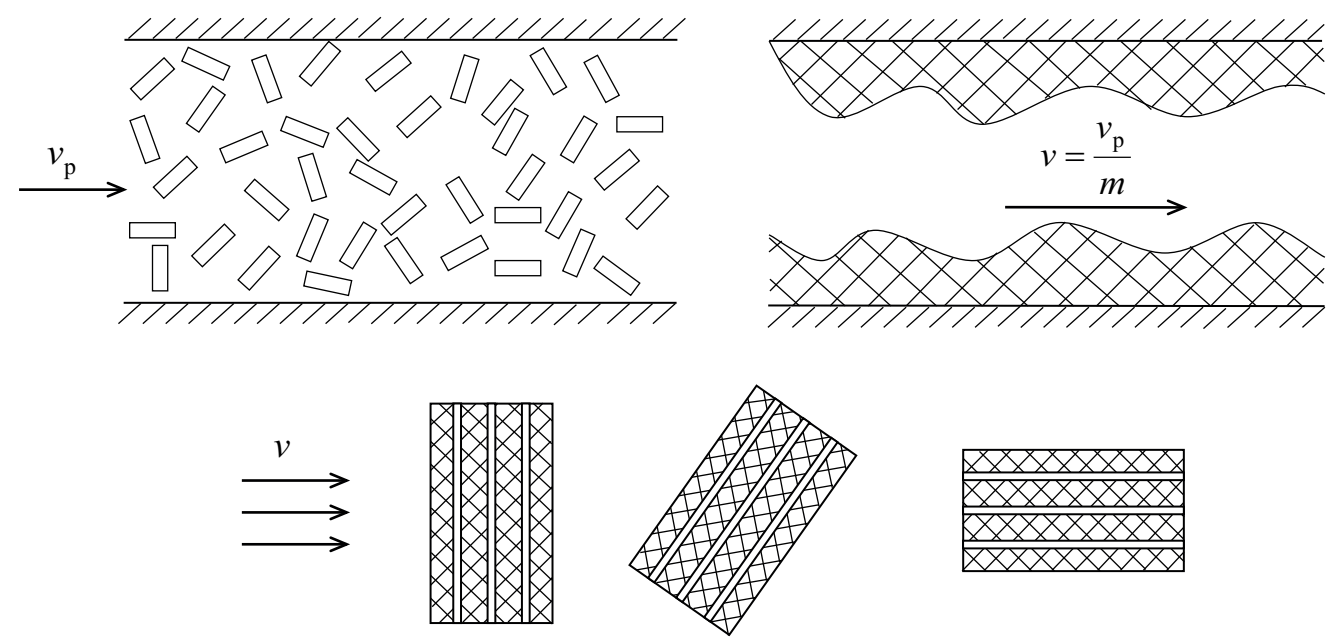

Fig. 5. Filling of grained powder

The research was done under the state assignment No 1.1481.2014/K, registration number is 114072170012 from 21.07.2014.

\section{References}

1. Boltrukevich E.N., Ratanov G.S. [Experimental Determination of An Average Particle Size of the Condensed Phase in the Combustion Products of Black Gunpowder]. FGB, 1979, no 2, pp. 187-188. (in Russian)

2. Rusyak I.G., Ushakov V.M. [Intrachamber Heterogeneous Processes in Barrel Systems]. Ekaterinburg, UrO RAN Publ., 2001. (in Russian)

3. Koshkin V.K. [Fundamentals of Heat Transfer in the Aviation and Rocket-Space Technology]. Moscow, Mashinostroenie Publ., 1975. (in Russian)

4. Aerov M.E., Todes O.M. [Hydraulic and Thermal Basics of Machines Working with Steady and Fluidized Granular Layer]. Leningrad, Himiya Publ., 1968. (in Russian)

5. Gorbis Z.R. [Heat Exchange and Hydrodynamics of Disperse Throughflows]. Moscow, Energiya Publ., 1970. (in Russian)

6. Shcherbina Iu.A., Gorbunov G.I. [About Aerodynamic Resistance of Burning Particles with Spherical Form]. Tr. MFTI, 1962, no 9, pp. 9-15. (in Russian) 
7. Basov V.N., Popov V.A. [About Resistance Coefficient to Movement of Burning Particles]. Izv. Akad. Nauk SSSR OTN, 1958, no 8, pp. 12-14.(in Russian)

8. Gol'dshtik M.A. [Theory of Concentrated Disperse Systems]. Mat-ly Mezhdunar. Shkoly po protcessam perenosa $v$ nepodvizhnykh $i$ psevdoozhizhennykh zernistykh sloyakh [Materials of Intern. School on Transport Processes in Fixed and Fluidized Grained Layers]. Minsk, 1977, pp. 49-84. (in Russian)

9. Spolding D.B. [Convective Mass Transfer]. Moscow, Energiya Publ., 1965. (in Russian)

10. Isachenko V.P., Osipova V.A., Sukomel A.S. [Heat Transfer]. Moscow, Energoizdat Publ., 1981. (in Russian)

11. Lengmiur I. [Deposition Efficiency on Streamlined Bodies]. [In Book Physics of Precipitation Formation], Moscow, IL, 1951. (in Russian)

12. Friedlander S.K. Deposition of Suspended Particles from Turbulent Gas Streams. Ind. And Eng. Chem., 1957, no. 7, p. 1151.

13. Kutateladze S.S., Borishanskii V.N. [Reference Book on Heat Transfer]. Moscow, Gostehizdat Publ., 1959. (in Russian)

14. Ginzburg I.P. [The Theory of Resistance and Heat Transfer]. Leningrad, LGU Publ., 1970. (in Russian)

15. Sorkin R.E. [Gas and Thermal Dynamics of Rocket Engines for Solid Fuel]. Moscow, Nauka Publ., 1967. (in Russian)

16. Staniukovich K.P. [Unsteady Movements of a Continuous Medium]. Moscow, Nauka Publ., 1971. (in Russian)

17. Zel'dovich Ia.B. [To the Theory of Burning Gunpowders and Explosives]. ZHETF, 1942, vol. 12, no 11-12,pp. 18-29. (in Russian)

18. Zel'dovich Ia.B. [About Velocity of Gunpowder Combustion for Varying Pressure]. PMTF, 1964, no 3, pp. 126-138. (in Russian)

19. Novozhilov B.V. [Unsteady Combustion of Solid Rocket Propellants]. Moscow, Nauka Publ., 1973. (in Russian)

20. Erohin B.T. [Theory of Intrachamber Processes and Designing of SPRM]. Moscow, Mashinostroenie Publ., 1991. (in Russian)

21. Zel'dovich Ia.B. [To the Theory of Gunpowder Combustion in a Gas Flow]. FGV, 1971, vol. 7, no 4, pp. 163-176. (in Russian)

22. Korner J. [Internal Ballistics of Guns]. Moscow, IL Publ., 1953. (in Russian)

23. Vandenkerkhove J. [Erosive Burning of Solid Colloidal Fuels]. VRT, 1959, no 3(51), pp. 70-78. (in Russian) 
24. Vilyunov V.N. [To the Theory of Erosive Burning of Gunpowders]. DAN SSSR, 1961, vol. 136, no 2, pp. 381-384. (in Russian)

25. Lenoir Zh., Robilliard J. [Mathematical Method for Determining the Parameters of Erosive Burning in Rocket Engines on Solid Fuel]. [Questions to Burning of Rocket Fuels], 1959, no 2, pp. 405-413. (in Russian)

26. Karakozov G.K. [Investigation of Inflation Process During Burning of Mixed Fuels]. Dis. ... kand. tekhn. nauk, 1964. (in Russian)

27. Nelaev V.P. [Combustion of Ballistic Fuels in Blowing Conditions by Gunpowder Gases at High Pressures]. Dis. ... kand. tekhn. nauk, 1975. (in Russian)

28. Vilyunov V.N., Kolmakov V.N. [About Combustion Velocity of Rocket Gunpowders in a Turbulent Flow of Gases]. Dom tekhniki. Trudy SFTI, 1963, no 43, pp. 87-98. (in Russian)

29. Merzhanov A.G., Dubovitckiy F.I. [To the Theory of Stationary Combustion of Gunpowder]. DAN SSSR, 1959, vol. 129, no 1, pp. 153-157. (in Russian)

30. Viliunov V.N. [To the Mathematical Theory of Stationary Burning Velocity of Condensed Matter]. DAN SSSR, 1961, vol. 136, no 1, pp. 136-139. (in Russian)

31. Novozhilov B.V. [The Distribution Velocity of the Front of the Exothermic Reaction in the Condensed Phase]. DAN SSSR, 1961, vol. 141, no 1, pp. 151-153. (in Russian)

Ivan G. Rusyak, Doctor of Technical Sciences, Professor, Head of Department of Mathematical Support for Information Systems, Kalashnikov Izhevsk State Technical University, Izhevsk, Russian Federation, primat@istu.ru.

Received November 20, 2014 